\title{
New method for quantitative analysis of GD2 ganglioside in plasma of neuroblastoma patients ${ }^{\star}$
}

\author{
Dominik Czaplicki ${ }^{1}$, Irena Horwacik ${ }^{1}$, Aleksandra Kowalczyk ${ }^{1}$, \\ Aleksandra Wieczorek ${ }^{2}$, Katarzyna Bolek-Marzec², Walentyna Balwierz², \\ Andrzej Kozik ${ }^{3}$ and Hanna Rokita ${ }^{1 凶}$ \\ ${ }^{1}$ Laboratory of Molecular Genetics and Virology, Faculty of Biochemistry, Biophysics and Biotechnology, \\ Jagiellonian University, Kraków, Poland; ${ }^{2}$ Department of Paediatric Oncology and Haematology, University \\ Children's Hospital, Collegium Medicum, Jagiellonian University, Kraków, Poland; ${ }^{3}$ Department of Analytical \\ Biochemistry, Faculty of Biochemistry, Biophysics and Biotechnology, Jagiellonian University, Kraków, Poland
}

Received: 07 April, 20009; revised: 13 July, 2009; accepted: 11 August, 2009

available on-line: 31 August, 2009

\begin{abstract}
Neuroblastoma, the most common extracranial solid tumour of childhood, is a malignancy of unknown origin and non-specific symptoms. One of the markers of the disease is GD2 ganglioside (disialoganglioside), which is abundantly expressed on the surface of neuroblastoma cells. Gangliosides are known to be shed by tumour cells and this phenomenon can be significant in cancer progression as they inhibit a number of immune responses both in vitro and in vivo. In search for novel markers useful in monitoring and prognosis of neuroblastoma, we developed and validated a new quantitative method of GD2 ganglioside analysis in human blood plasma. We evaluated the level of gangliosides in blood serum of 34 neuroblastoma patients using highperformance liquid chromatography. The technique was used to detect fluorescently labelled oligosaccharides derived from serum glycosphingolipids by enzymatic digestion with ceramide glycanase. The developed method allowed determination of GD2 concentrations at the picomole level and required only $40 \mu \mathrm{l}$ of plasma, which should be particularly useful when the quantity of clinical material is limiting. Moreover, this method can be applied to study concentration of other gangliosides, as shown for GD3 ganglioside. Analysis of plasma samples from the 34 neuroblastoma patients did not reveal any correlations between the concentration of GD2 ganglioside and clinical parameters, including the results of therapy; it showed, however, that the concentration of GD2 ganglioside in the plasma of neuroblastoma patients decreased substantially in the course of treatment.
\end{abstract}

Keywords: gangliosides, neuroblastoma, human blood plasma, HPLC, quantitative analysis

\section{INTRODUCTION}

Neuroblastoma (NB) is a paediatric neoplasm that occurs mostly in children less than 5 years old. The disease develops from precursor cells of the peripheral nervous system and the primary tumour is usually located in adrenal glands, but may also occur in other sympathetic neuron sites. NB is the most common extracranial solid tumour of childhood, with 6-11 new cases each year per million children aged 0-15 years. In Poland, about 60 new cases of NB are diagnosed annually (Balwierz, 2004). Aetiology of the disease remains unknown. At diagnosis, the disease is usually spread to metastatic foci,

\footnotetext{
$\square$ Corresponding author: Hanna Rokita, Laboratory of Molecular Genetics and Virology, Faculty of Biochemistry, Biophysics and Biotechnology, Jagiellonian University, ul. Gronostajowa 7, 30-387 Kraków, Poland; phone: (48) 12 664 6337; fax: (48) 12664 6902; e-mail: hanna.rokita@uj.edu.pl

*Presented at the XXXVI Winter School "Molecule interactions in health and disease" organized by the Faculty of Biochemistry, Biophysics and Biotechnology, Jagiellonian University, 21-26 February, 2009, Zakopane, Poland.

Abbreviations: FBS, fetal bovine serum; FITC, fluorescein isothiocyanate; GU, glucose units; HPLC, high performance liquid chromatography; LDH, lactate dehydrogenase; MFI, mean fluorescence intensity; NB, neuroblastoma; NSE, neurospecific enolase; PBS, phosphate-buffered saline.
} 
primarily in the lymph nodes and bone marrow and bones. Nevertheless, NB has the highest rate of spontaneous remission among all human tumours. NB in infants may occur with a specific pattern of metastases to liver and skin, but in spite of this the disease has favourable prognosis and usually responds well to chemotherapy or spontaneously undergoes complete remission (Evans et al., 1981). In contrast, the prognosis of metastatic disease in children over 1 year old is bad. The current treatment protocols of NB are based on chemotherapy combined with surgical removal of the tumour. Irradiation is used as a complementary therapy. In cases with bad prognosis, megachemotherapy followed by autologous bone marrow transplant is used to destroy residual cancer cells. Despite intensive treatment, the longterm survival in advanced NB is as low as 30\% (Balwierz, 2004). The major challenge is the treatment of minimal residual disease associated with incomplete removal of tumour cells by chemo- and radiotherapy (Beiske et al., 2005). New therapeutic options are under development, including: passive immunotherapy, radioimmunotherapy, tyrosine kinase inhibitors and anti-angiogenic therapies (Brodeur, 2003).

Prognostic factors in NB. The clinical course of NB can be very heterogeneous and a number of factors have been found relevant for prognosis and monitoring of the disease. Two most important factors are: patient's age at diagnosis and stage of the disease. The biological features of NB in infants are different than in older children ( $>1$ y.o.). In most infants the metastatic form of the disease can be successfully treated with limited chemotherapy or solely with surgical procedure, while patients more than 1 year old require a much more aggressive treatment. Depending on the advancement of the disease, NB is staged from 1 to 4 according to the International Neuroblastoma Staging System. In some cases, particularly in infants, the tumour undergoes spontaneous remission (NB stage $4 S$ ), while in older children it may differentiate to a benign form of ganglioneuroma. Histology of the tumour is also of prognostic significance; in NB two histological types have been defined: favourable and unfavourable, depending on the degree of differentiation and the mitotic index (Shimada et al., 1999). Serum levels of three biochemical markers - ferritin, lactate dehydrogenase (LDH) and neurospecific enolase (NSE) - seem to be significant in NB; elevated concentrations of those markers are associated with worse prognosis (Riley et al., 2004). Several genetic markers are important prognostic factors in NB; those include MYCN oncogene amplification, genome ploidy and chromosomal aberrations in the tumour cells (Weinstein et al., 2003).

Gangliosides of malignant cells. Gangliosides are a class of complex molecules belonging to glycosphingolipids. Their structure is formed by the ceramide core and a sugar chain of several carbohydrate residues, including at least one sialic acid. Ganglioside biosynthesis is a complex enzymatic pathway (d'Azzo et al., 2006). Gangliosides are components of eukaryotic cell membranes - mainly in the central nervous system, but are also found on the surface of cancer cells. However, ganglioside expression in malignant cells is often altered. For example, the number and linkage of sialic acids can change, leading to production of atypical glycolipid molecules (Varki, 1999). Moreover, in many cancers such as melanoma, soft tissue sarcoma and small cell lung cancer the pathway of ganglioside synthesis is shortened, which is manifested by overexpression of simpler forms such as GM3, GD3, GM2 and GD2 (Hettmer et al., 2003; nomenclature according to Svennerholm, 1980). This phenomenon is related to neoplastic transformation, e.g., GD3 ganglioside is abundant on melanoma cells, but only small quantities are present on normal melanocytes (Carubia et al., 1984). Ganglioside overexpression may occur in more than $90 \%$ of cases of a particular type of cancer (Chang et al., 1992). Differentiation of tumour cells induced in vitro leads to the restoration of a normal expression profile of gangliosides (Liour et al., 2000).

Surface gangliosides can be shed from the cell membranes in a number of ways - gangliosides may be released in the form of micelles and aggregates (Kong et al., 1998) as well as complexes with antibodies (Hakansson et al., 1985) and plasma proteins (Valentino \& Ladisch, 1992). Ganglioside shedding seems to have biological importance - there are reports that the circulating gangliosides are able to weaken cellular immunity and thereby accelerate tumour progression (Sietsma et al., 1998). Several mechanisms of immunosuppression are possible: loss of antigen from the surface of cancer cells, blocking of specific antibodies and $\mathrm{T}$ cell receptors or direct suppression of patient's lymphocytes (Ladisch et al., 1994). Some gangliosides may also inhibit the biological activity of cytokines, such as interleukin 2 (Ravindranath et al., 2001).

GD2 ganglioside in neuroblastoma. GD2 ganglioside (disialoganglioside) is one of the antigens associated with NB. Chemically, GD2 is a derivative of cerebroside containing two sialic acid residues; the structure of GD2 is: GalNAc $\beta 1 \rightarrow 4$ (Neu5Ac $\alpha 2 \rightarrow$ 8) (Neu5Ac $\alpha 2 \rightarrow 3$ ) Gal $\beta 1 \rightarrow 4 \mathrm{Glc} \beta 1 \rightarrow 1^{\prime}$-ceramide (Fig. 1). The antigen is characteristic to cells of neuroectodermal origin and its normal distribution in the human organism is limited to neurons and peripheral nerve fibres (Varki, 1999). The GD2 content on NB cells is particularly high and may reach up to $30 \%$ of all gangliosides present on the cell surface (Wu et al., 1986). In addition, the antigen is shed from the tumour cell and released into the bloodstream ( $\mathrm{Li}$ 


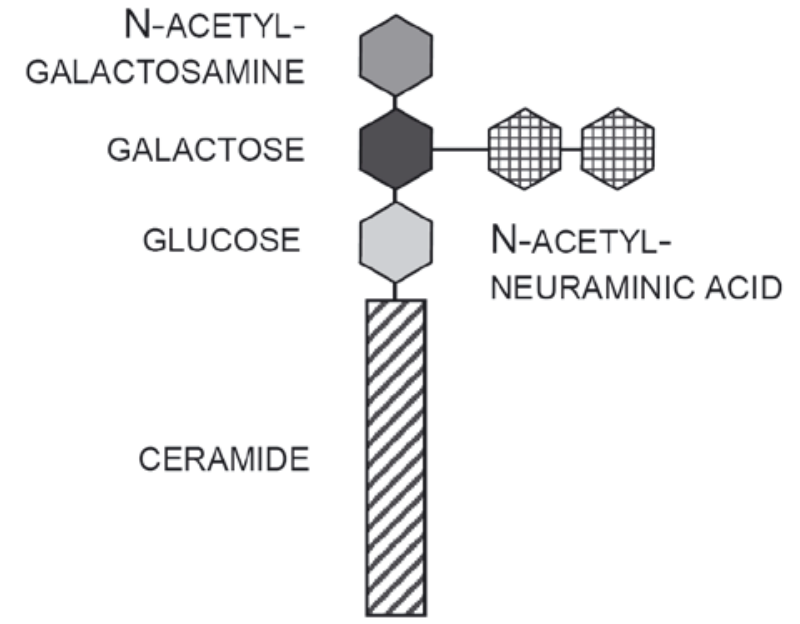

Figure 1. Schematic chemical structure of GD2 ganglioside.

\& Ladisch, 1991), and its concentration in the blood may be correlated with progression of the disease (Ladisch et al., 1987). It has been suggested that the increased shedding of GD2 ganglioside and MYCN amplification jointly characterise the aggressive type of NB cells (Valentino et al., 1990).

\section{MATERIALS AND METHODS}

Cell lines. A hybridoma cell line producing 14G2a murine monoclonal antibody specific to GD2 ganglioside (Mujoo et al., 1989) was a kind gift from Dr. R. A. Reisfeld from the Scripps Institute (La Jolla, CA, USA). HTLA-230 cell line was a kind gift from Professor Vito Pistoia from the Gaslini Institute (Genova, Italy). IMR-32, BE(2)-C, SH-SY5Y and SKMEL-28 cell lines were obtained from ATCC.

Clinical samples. A total of 42 blood serum samples from 34 patients diagnosed with different stages of NB were collected between 2003 and 2008 at the Department of Paediatric Oncology and Haematology of the University Children's Hospital (Kraków, Poland). In six cases, two different samples were obtained from the same patient, and in one case - three samples from the same patient. Where possible, the samples were collected before treatment, after treatment and at a follow-up time point (14-33 months after treatment). Samples were also collected from seven patients with non-neuroblastoma disease; those samples were used as controls in HPLC analysis (non-NB). Collection of clinical samples was authorised by the Bioethical Commission of the Jagiellonian University (opinion no. KBET/311/B/2002, prolonged accordingly).

Characteristics of patients. Clinical parameters were gathered on the basis of available medical records. In the group of 34 patients, 17 were male
(50\%) and 17 female (50\%). Age of patients at the time of diagnosis ranged from 39 days to 12 years, median 22.3 months. Twelve (35.3\%) and 22 (64.7\%) patients were in the age group below 1 year of age and above 1 year of age, respectively. NB was staged in all patients according to the International Neuroblastoma Staging System: the largest group - $19(55.9 \%)$ patients - were patients with stage 4 NB; $1(2.9 \%), 5(14.7 \%)$ and $7(20.6 \%)$ patients were diagnosed in stages 1, 2 and 3, respectively; 2 (5.9\%) patients had NB stage 4S. MYCN gene amplification was observed in $4(11.8 \%)$ patients, for another $4(11.8 \%)$ MYCN analysis results were not available and in the remaining 26 patients $(76.4 \%)$ normal copy number of MYCN was found. The histological type of the tumour, assessed according to the International Neuroblastoma Pathology Classification criteria, was found to be favourable in 13 (38.2\%) patients and unfavourable in $14(41.2 \%)$ patients; in other cases, histopathological evaluation was not possible. The patients exhibited high variability of biochemical parameters: the level of LDH in plasma varied in the range 393-5966 IU/1 (mean 2049.4 IU/1), while NSE levels in plasma ranged from 0 to $1122.8 \mathrm{ng} / \mathrm{ml}$, with an average value of $200.7 \mathrm{ng} / \mathrm{ml}$. All patients with NB were treated according to the current European SIOPEN protocols with the following results: 29 patients survived (24 with no disease progression, 5 after progression or in relapse, in two cases - early stage treatment), 5 patients died (4 as a result of progression, 1 due to complications).

Isolation of blood plasma. Plasma was isolated by centrifugation in density gradient. Blood $(5 \mathrm{ml})$ was layered on $5 \mathrm{ml}$ of Ficoll (density 1.077 $\mathrm{g} / \mathrm{cm}^{3}$ ) in a $15-\mathrm{ml}$ tube. The tube was then centrifuged for $30 \mathrm{~min}$ at $800 \times \mathrm{g}$ at room temperature. After separation the plasma was collected as the upper phase.

Lipid extraction and isolation of gangliosides. Plasma samples $(40 \mu \mathrm{l})$ or cell pellets $\left(5 \times 10^{5}\right)$ were extracted with $4 \mathrm{ml}$ of a mixture of chloroform/methanol, 2:1 (v/v) and shaken vigorously for $15 \mathrm{~s}$ in a glass tube. The solution was sonicated for $15 \mathrm{~min}$ in an ultrasonic water bath at $22^{\circ} \mathrm{C}$ and then incubated on ice for $2 \mathrm{~min}$. The samples were centrifuged for $10 \mathrm{~min}$ at $4^{\circ} \mathrm{C}$ and $3200 \times \mathrm{g}$. The supernatant was transferred to a clean tube and dried under a stream of nitrogen. Then, after dissolving in 200 $\mu \mathrm{l}$ of chloroform, the obtained mixture of lipids was applied to a column containing $0.1 \mathrm{~g}$ silicic acid in $1 \mathrm{ml}$ of chloroform. Specific lipid fractions were sequentially eluted from the column with $5 \mathrm{ml}$ of chloroform (neutral lipids), $1.8 \mathrm{ml}$ of methanol/acetone mixture, $1: 9(\mathrm{v} / \mathrm{v}$; neutral glycolipids) and $1.8 \mathrm{ml}$ of methanol (gangliosides). The last fraction, containing gangliosides, was dried in a vacuum concentrator and then dissolved in $10 \mu \mathrm{l}$ of buffer for enzyme di- 
gestion, which consisted of $1 \mathrm{mg} / \mathrm{ml}$ sodium cholate dissolved in $50 \mathrm{mM}$ sodium acetate, $\mathrm{pH}$ 5.0.

Enzymatic digestion of gangliosides. After complete dissolution of the sample, $10 \mu \mathrm{l}$ of ceramide glycanase solution (Merck Biosciences) was added at a concentration of $5 \mathrm{U} / \mathrm{ml}$, which gave the final activity of $0.05 \mathrm{U}$ per sample. The enzymatic reaction lasted for $18 \mathrm{~h}$ and was conducted at $37^{\circ} \mathrm{C}$.

Glycan purification. After completion of digestion, the glycans in the reaction mixture were separated from the ceramide, enzyme and other contaminants by column purification using an Oasis HLB $10 \mathrm{mg}$ cartridge (Waters). The column resin was activated beforehand with $1 \mathrm{ml}$ of methanol and equilibrated with $1 \mathrm{ml}$ of HPLC grade water; $180 \mu \mathrm{l}$ of HPLC grade water was added to the reaction mixture and the entire solution was transferred to the Oasis column. The reaction tube was washed with $50 \mu \mathrm{l}$ of water which was then transferred to the column. The column was washed with $200 \mu \mathrm{l}$ of $5 \%(\mathrm{v} / \mathrm{v})$ methanol in HPLC grade water and the combined eluate was dried in a vacuum concentrator.

Fluorescent labelling of glycans. The purified glycan samples were labelled with 2-aminobenzamide using the GlycoProfile 2-AB Labeling Kit (Sigma-Aldrich) according to the manufacturer's instructions.

High performance liquid chromatography. Labelled glycan samples were diluted by adding $200 \mu$ l of HPLC grade water. A Shimadzu model 10AVP HPLC system was used for chromatography, equipped with a $105 \times 4.6 \mathrm{~mm}$ Hypersil ODS(C18) $3 \mu \mathrm{m}$ column (Phenomenex, Cat. No. 00F-0145-E0). Reversed-phase HPLC was performed in a two-phase system in which phase A was $50 \mathrm{mM}$ formic acid brought to $\mathrm{pH} 5.0$ with triethylamine, while phase B consisted of a $1: 1$ mixture of phase A and HPLC grade acetonitrile. The injection volume for each sample was $180 \mu \mathrm{l}$. A gradient with the following time programme was used: $\mathrm{t}=0 \mathrm{~min}$, flow $0.5 \mathrm{ml} / \mathrm{min}, 95 \%$ phase $\mathrm{A} ; \mathrm{t}=30 \mathrm{~min}, 0.5 \mathrm{ml} / \mathrm{min}, 95 \%$ phase $\mathrm{A} ; \mathrm{t}=95$ $\mathrm{min}, 0.5 \mathrm{ml} / \mathrm{min}, 90 \%$ phase $\mathrm{A} ; \mathrm{t}=100 \mathrm{~min}, 0.5$ $\mathrm{ml} / \mathrm{min}, 76 \%$ phase $\mathrm{A} ; \mathrm{t}=101 \mathrm{~min}, 1.5 \mathrm{ml} / \mathrm{min}$, $5 \%$ phase $\mathrm{A} ; \mathrm{t}=107 \mathrm{~min}, 1.5 \mathrm{ml} / \mathrm{min}, 5 \%$ phase $\mathrm{A} ; \mathrm{t}=108 \mathrm{~min}, 1.5 \mathrm{ml} / \mathrm{min}, 95 \%$ phase $\mathrm{A} ; \mathrm{t}=112$ $\min , 1.5 \mathrm{ml} / \mathrm{min}, 95 \%$ phase $\mathrm{A} ; \mathrm{t}=113 \mathrm{~min}, 0.5 \mathrm{ml} /$ min, $95 \%$ phase A; total time: $114 \mathrm{~min}$. Following column separation, the labelled glycans were detected using a Shimadzu RF-10AXL fluorescence detector with excitation wavelength of $330 \mathrm{~nm}$ and the emitted signal was measured at $420 \mathrm{~nm}$. Chromatograms were recorded and analyzed using Shimadzu Class VP software ver. 6.

Qualitative analysis of HPLC data. Qualitative analysis was based on a comparison of the re- tention times of detected components with the retention times of standards, which were glycans isolated from commercially available gangliosides GM1, GM3, GD2, GD3 (Merck Biosciences) and a mixture of gangliosides from bovine brain (Sigma-Aldrich). In order to confirm the validity of the method, the retention times obtained for the standards were compared with previously published values (Wing et al., 2001). Due to the differences in methodology, the retention time was converted into glucose units (GU). Fluorescently labelled samples of arabinobiose (Megazyme) with GU=2 and arabinotriose (Megazyme) with $\mathrm{GU}=3$ were used as reference samples. The values compared were in agreement with the published data, which provided evidence of good reproducibility of the method. GD2 ganglioside analysis by HPLC has not been published previously, so the value of $2.48 \mathrm{GU}$ obtained for the GD2 retention time cannot be compared with any available studies (Table 1).

Quantitative analysis of HPLC data. On the basis of quantitative analysis of samples containing standards of known ganglioside content, a relationship between fluorescence signal and the amount of ganglioside was established. For GD2 ganglioside, a peak area of 1000000 corresponded to 16 pmol. For GD3 ganglioside, a peak area of 1000000 corresponded to $1.25 \mathrm{nmol}$. Those values were used to convert the fluorescence signal to the ganglioside concentration in the plasma samples.

GD2 ganglioside analysis by flow cytometry. For additional confirmation of the quantitative HPLC analysis, flow cytometry was used as a reference method, as it allows quantitative assessment of antigen expression. One hundred thousand cells of five selected human cell lines (IMR-32, HTLA230, BE(2)-C, SH-SY5Y - neuroblastoma, SK-MEL28 - melanoma) were suspended in phosphatebuffered saline (PBS) with 10\% foetal bovine serum (FBS) and centrifuged at $800 \times g$. Subsequently, the cells were suspended in a solution of 14G2a murine monoclonal antibody at a concentration of $1 \mu \mathrm{g} / \mathrm{ml}$ in PBS with $10 \%$ FBS. After a 45 -min incubation on ice, samples were centrifuged again and washed twice with cold PBS with 10\% FBS. 14G2a antibodies bound to cell surface were detected using $\left(\mathrm{Fab}^{\prime}\right)_{2}$ antibody fragments coupled with fluorescein isothiocyanate (ICN, Cat. No. 55526). Secondary antibodies used were diluted 1:40 in PBS with 10\% FBS for 45 min on ice. After washing the cells were suspended in PBS with 10\% FBS and analysed with a FACScan cytometer (BD Biosciences) equipped with Cellquest software. The level of GD2 ganglioside expression was presented as the fluorescence index, according to the formula:

[fluorescence index $]=([\%$ positive cells $] \times \mathrm{MFI}) / 100 \%$ 
Table 1. Comparison between qualitative results produced with the method described in this work and results published by Wing et al., 2001.

Retention time was expressed in glucose units (GU); by definition, retention time equals 2.00 GU for arabinobiose and 3.00 GU for arabinotriose.

\begin{tabular}{lll}
\hline Standard sample & $\begin{array}{l}\text { Retention time } \\
\text { published by Wing et al., 2001 [GU] }\end{array}$ & $\begin{array}{l}\text { Retention time } \\
\text { measured with the described method [GU] }\end{array}$ \\
\hline GM1 & 1.91 & 2.01 \\
Arabinobiose & 2.00 & 2.00 \\
GM3 & 2.04 & 2.11 \\
GD1b & 2.34 & 2.28 \\
GD3 & 3.00 & 2.78 \\
Arabinotriose & 3.00 & 3.00 \\
GD1a & 3.26 & 3.14 \\
GT1b & 3.73 & 3.73 \\
GD2 & not measured & 2.48 \\
\hline
\end{tabular}

where MFI is mean fluorescence intensity of the sample. The values obtained for the five cell lines were then compared with the result of HPLC analysis performed on samples of the same cells.

Statistical analysis: Arithmetic mean was the estimator of the expected value. Student's $t$-test was used to compare the average values: $P$-value of 0.05 was the significance level cut-off, and for $P$-values in the range of $0.05-0.10$ the results were interpreted as a trend indication. Correlation between data sets was assessed using the squared Pearson's correlation coefficient. The Excel spreadsheet, a part of Microsoft Office 2003 package, was used for statistical analysis.

\section{RESULTS}

\section{Quantitative analysis of GD2 ganglioside}

HPLC analysis was performed for all samples from the NB patients, as well as control nonNB samples. The concentration of GD2 ganglioside in serum samples of patients with NB ranged from 0 to $3940 \mathrm{pmol} / \mathrm{ml}$, with an average value of 660.7 $\mathrm{pmol} / \mathrm{ml}$ for all 42 samples analysed. The mean concentration for samples collected prior to treatment was $591.4 \mathrm{pmol} / \mathrm{ml}$ (31 samples), for those collected after treatment - $1156.1 \mathrm{pmol} / \mathrm{ml}$ (7 samples), and for follow-up samples - $330.3 \mathrm{pmol} / \mathrm{ml}$ (4 samples). The average GD2 content in serum of non-NB patients was $106.1 \mathrm{pmol} / \mathrm{ml}$ (7 samples). The results indicate a substantial difference in GD concentrations between serum samples from NB patients and age-matched non-NB patients. The concentration of GD2 in NB samples was on average 6.2 times higher than in non-NB samples (660.7 pmol/ml versus 106.1 $\mathrm{pmol} / \mathrm{ml})$, but the difference was not statistically significant.

\section{Correlations with known prognostic factors and other parameters}

The analysis also showed that among the 31 patients from whom serum samples were collected before treatment, 14 (45.2\%) had elevated GD2 concentrations in plasma as compared to non-NB samples (over $106.1 \mathrm{pmol} / \mathrm{ml}$ ), and the average value for this group was $1239 \mathrm{pmol} / \mathrm{ml}$. Nevertheless, statistical analysis failed to reveal any direct correlations with known prognostic factors. In patients with favourable tumour histology, the average level of GD2 in plasma was $623.1 \mathrm{pmol} / \mathrm{ml}$, while in the group with unfavourable histology - $511.0 \mathrm{pmol} / \mathrm{ml}$. The mean value for patients younger than 1 year was $360.3 \mathrm{pmol} / \mathrm{ml}$, while for patients older than 1 year - $718.6 \mathrm{pmol} / \mathrm{ml}$. In patients with MYCN oncogene amplification in the tumour, GD2 concentration in plasma was $24.1 \mathrm{pmol} / \mathrm{ml}$ on average, while it was $729.5 \mathrm{pmol} / \mathrm{ml}$ for cases with no MYCN amplification. The differences between the compared groups were not statistically significant. The concentration of GD2 in the plasma of patients before treatment was $595.7 \mathrm{pmol} / \mathrm{ml}$ for patients with NB stages 1-3, while for patients in stage 4 (excluding 4 ) it was $564.2 \mathrm{pmol} / \mathrm{ml}$. There were no statistically significant differences between these groups. The average result for patients in stages 1-4 (excluding 4S) was 591.4 $\mathrm{pmol} / \mathrm{ml}$. The average content of GD2 ganglioside according to sex of patients was as follows: female - $707.9 \mathrm{pmol} / \mathrm{ml}$, male - $467.2 \mathrm{pmol} / \mathrm{ml}$. Also that difference was not statistically significant.

\section{Changes of GD2 level during treatment}

Analysis of chromatograms obtained for different samples from the same patient allowed tracking of changes in GD2 concentrations in the course of treatment (Fig. 2). The GD2 concentration in the plasma decreased substantially during treatment. 
A)
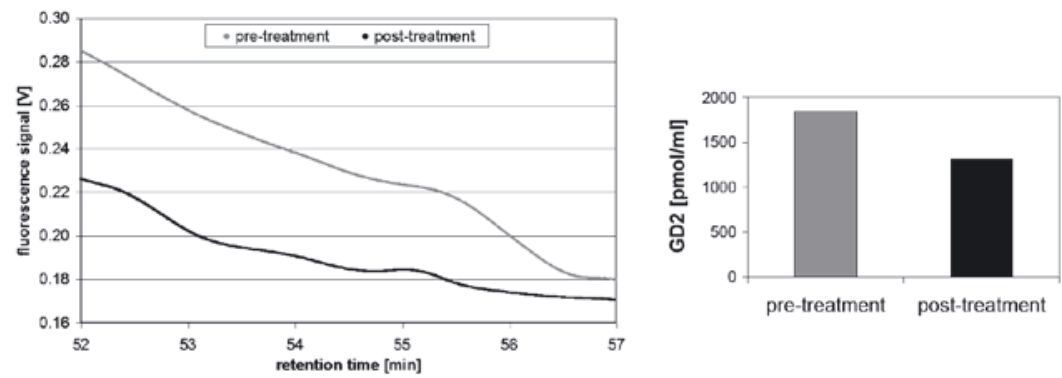

B)
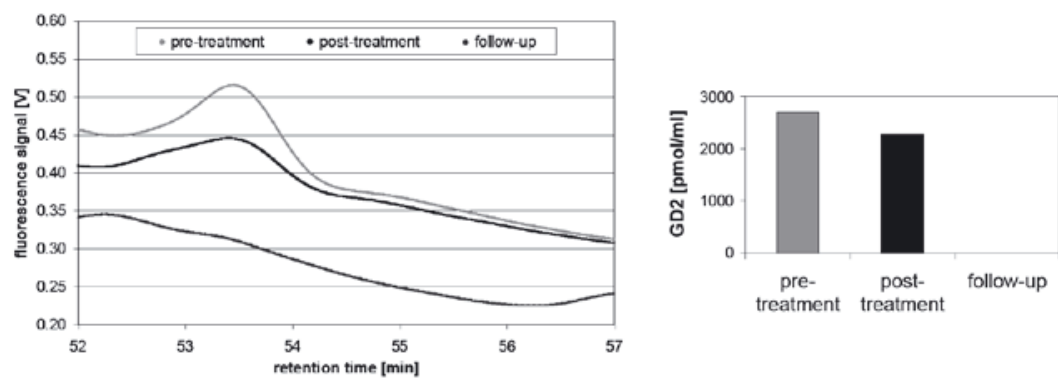

C)
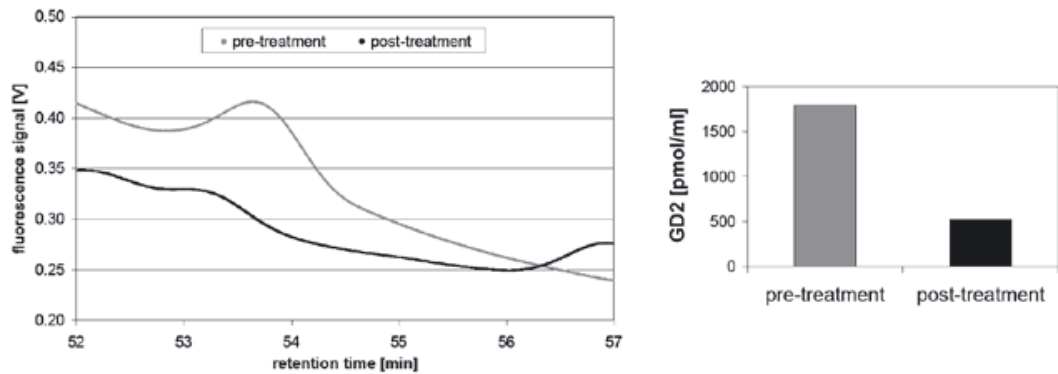

D)
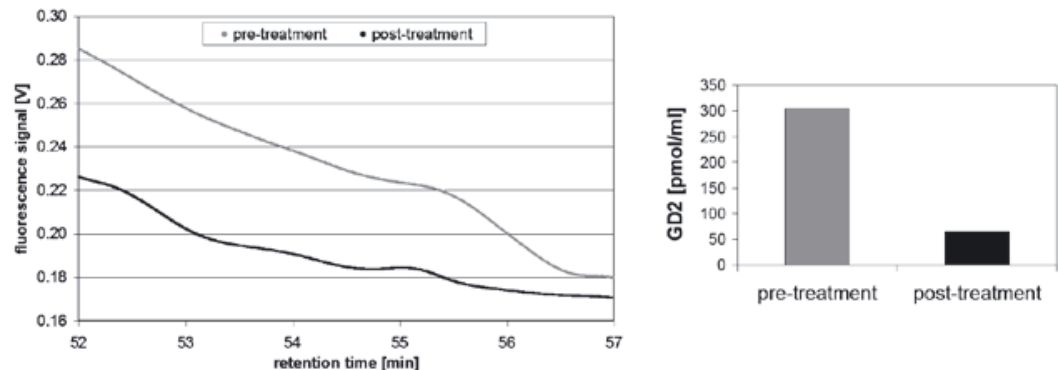

E)

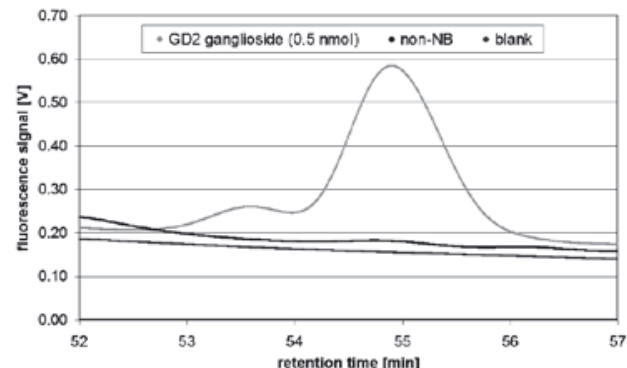

Figure 2. GD2 level in serum samples of four patients for whom both pre-treatment and post-treatment samples were available.

The following changes in GD2 level were detected throughout therapy: 29\% decrease for patient A, 16\% decrease followed by diminishing to undetectable level for patient B, $71 \%$ decrease for patient $\mathrm{C}$ and $88 \%$ decrease for patient $\mathrm{D}$; panel E, reference samples (GD2 standard, non-NB sample, blank sample). 

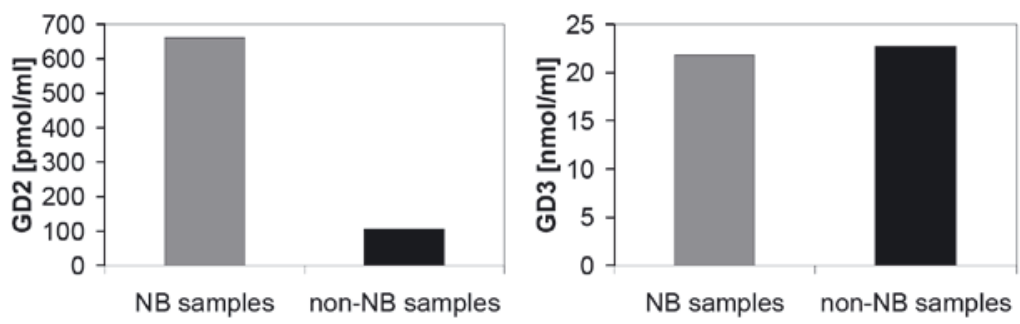

Figure 3. GD2 and GD3 ganglioside concentration in plasma samples.

Mean ganglioside concentration in plasma samples for GD2 (left) and GD3 (right) ganglioside; NB - patients with neuroblastoma, non-NB - other paediatric patients. The concentration of GD2 ganglioside in NB samples ( $\mathrm{n}=42)$ ranged from 0 to $3940 \mathrm{pmol} / \mathrm{ml}$ with a mean value of $660.7 \mathrm{pmol} / \mathrm{ml}$. The average GD2 content in serum of 7 non-NB patients was $106.1 \mathrm{pmol} / \mathrm{ml}$.

The average GD2 level after treatment - calculated for the four patients from whom relevant samples were available - was $30 \%$ of the pre-treatment level. This may provide additional evidence that the level of GD2 ganglioside is correlated with the occurrence of active disease and the treatment leads to its decrease.

\section{Analysis of gangliosides other than GD2}

The method of glycolipid analysis with HPLC can be extended to other ganglioside species present in human plasma. With the use of appropriate standards, the analysis can be performed simultaneously for many types of gangliosides in the same plasma sample. In this work, GD3 ganglioside analysis was chosen for comparison with the GD2 concentration studies. The chemical structure of GD3 is similar to that of GD2, but GD3, unlike GD2, is present in normal blood plasma. The concentration of GD3 ganglioside was evaluated in all samples analysed for the content of GD2. The level of GD3 was approximately two magnitudes of order higher than the GD2 concentration. In plasma samples of NB patients GD3 concentration varied from 0 to 107.3

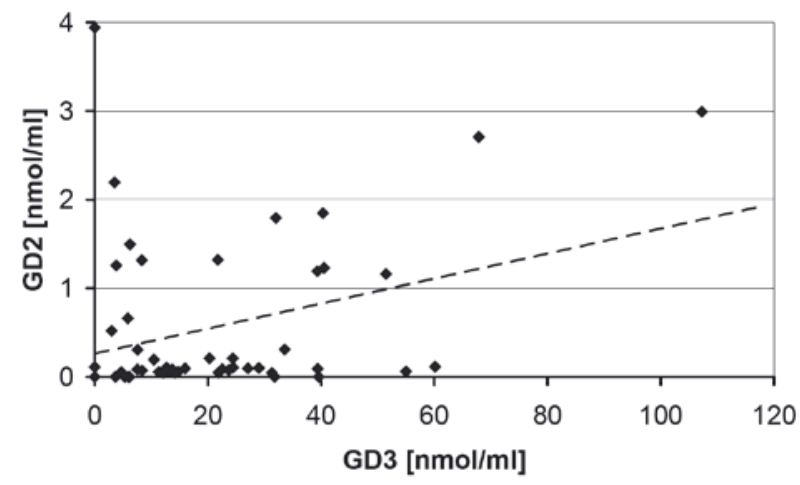

Figure 4. Correlation between GD2 and GD3 concentration in NB plasma samples.

The squared Pearson's correlation coefficient equals 0.1052 . $\mathrm{nmol} / \mathrm{ml}$, with an average value of $21.8 \mathrm{nmol} / \mathrm{ml}$ for all 42 samples analysed. The average level of GD3 in non-NB plasma samples was similar - $22.7 \mathrm{nmol} / \mathrm{ml}$ (7 samples). A comparison between average concentrations of GD2 and GD3 in NB and non-NB plasma samples is shown in Fig. 3. In 26 serum samples from NB patients the GD3 concentration was below the average for all NB samples $(21.8 \mathrm{nmol} / \mathrm{ml})$, while in 16 samples the GD3 level exceed this value. During treatment (as followed in 4 patients) the level of GD3 decreased in three cases by 79-91\%, and increased by about $74 \%$ in one case. There was no relation between the content of GD3 ganglioside and clinical factors such as sex, age, stage of disease or the outcome of treatment. The GD3 level showed no correlation with the level of GD2 measured in the same samples (Fig. 4).

\section{Comparison between HPLC analysis and flow cy- tometry results}

To confirm the quantitative nature of the chromatographic method, results of GD2 ganglioside analysis were compared with GD2 expression level estimated with a reference method of flow cytom-

Table 2. GD2 ganglioside analysis performed with HPLC and flow cytometry in five different cell lines.

HPLC results are expressed as fluorescence peak areas. Flow cytometry results are shown as fluorescence index. For flow cytometry, cells were stained with anti-GD2 murine monoclonal antibody and FITC-conjugated antimouse secondary antibodies. Cell lines: IMR-32, HTLA230, BE(2)-C, SH-SY5Y - neuroblastoma; SK-MEL-28 - melanoma.

\begin{tabular}{lll}
\hline Cell line & HPLC signal & Flow cytometry \\
\hline IMR-32 & 480129 & 431.5 \\
HTLA-230 & 574594 & 425.8 \\
BE(2)-C & 316726 & 345.2 \\
SH-SY5Y & 368343 & 339.1 \\
SK-MEL-28 & 0 & 4.2 \\
Correlation coefficient & $\mathrm{R}^{2}=0.9277$ & \\
\hline
\end{tabular}


etry, which is commonly used in antigen expression studies. Five different human cell lines were analysed simultaneously with both methods (Table 2). The results of the comparison suggest that HPLC analysis is a sensitive and quantitative method for GD2 ganglioside analysis.

\section{DISCUSSION}

The HPLC method developed for the purpose of this study can be used to detect gangliosides in plasma samples at the picomole level with the sample volume of less than $50 \mu$ l. It should be noted that the previously described methods based on thin-layer chromatography require approximately $1 \mathrm{ml}$ of plasma (Ladisch \& Gillard, 1987). In the case of small children the amount of blood that can be collected is limited. In addition, the novel HPLC method has a number of advantages, discussed below.

The results of GD2 concentration analysis are consistent with previously published data (Ladisch et al., 1987). Although no correlations between clinical data and the concentration of GD2 in the plasma of patients were found, it cannot be excluded that a longer period of observation following the therapy could lead to more definite conclusions. The search for new methods of prognosis is particularly important in the case of NB due to the minimal residual disease, which outlasts the treatment of advanced forms of this cancer and often leads to relapse.

The measured level of GD2 ganglioside is characterised by high variability among individual patients. Similar observations have already been published (Valentino et al., 1990), but more recent works suggest that the phenomenon of ganglioside shedding may be highly complex (e.g. Kong et al., 1998). The universal expression of GD2 ganglioside in NB tumours is a paradigm in NB biology ( $\mathrm{Wu}$ et al., 1986). However, it is not clear whether this assumption is fully justified. The level of GD2 expression in NB cells in vitro is varied (Chen et al., 2000); moreover, there have been reports of NB tumours that completely lack GD2 expression (SchumacherKuckelkorn et al., 2005) - a fact that can have significant clinical implications. It should be noted, however, that those publications have been much criticised by researchers in the field of NB diagnosis and therapy.

This HPLC method allows simultaneous analysis of a number of different species of plasma gangliosides. Potentially, it is possible to analyse serum samples from patients with other diseases. Ganglioside expression is altered in melanoma cells, in which the level of GM2, GD2 and GD3 gangliosides can be elevated (Hakomori, 2001). Other examples are: small cell lung cancer, astrocytoma, soft tissue sarcoma. Analysis of plasma gangliosides may be useful in prognosis of the disease (Perez et al., 2002). Extension of the analysis to other ganglioside species requires as little as an appropriate qualitative and quantitative standardisation by using high purity ganglioside preparations.

Simultaneous analysis of different gangliosides may have an additional aspect related to the biosynthesis pathway of b-series gangliosides: GD3 $\rightarrow$ GD2 $\rightarrow$ GD1b $\rightarrow$ GT1b $\rightarrow$ GQ1b. NB cell lines exhibit low expression of complex gangliosides (GD1b, GT1b, GQ1b) of this pathway (Hettmer et al., 2005). It seems that differences in the expression profile of b-series gangliosides may have a stronger clinical relevance than has the level of GD2 ganglioside alone (Hettmer et al., 2003). Under the influence of 13-cis-retinoic acid in vitro, NB cells change the ganglioside expression pattern towards more complex structures (Hettmer et al., 2004). 13-cis-retinoic acid is already used in the treatment of patients with NB, and a study of changes in the ganglioside synthesis during treatment is possible using the proposed analytical method, although it would require standardisation.

Reports published in recent years suggest that it is possible to further improve the sensitivity of the assay by using an alternative method of glycan labelling using 2-aminobenzoic acid and several further modifications (Neville et al., 2004).

HPLC may also be useful for the analysis of other components of the ganglioside biosynthesis pathway, such as ceramide and sphingosine (He et al., 2005). Studies confirm that high-performance liquid chromatography potentially has powerful applications in clinical practice, which offers hope for gradual improvement in diagnosis and prognosis of cancer on the basis of well-defined, measurable factors, in accordance with the concept of evidencebased medicine.

\section{Acknowledgements}

The authors are grateful to Anna Gołda, MSc for her invaluable help with the Shimadzu HPLC system.

The work was partially supported by research grant No. N401 114933 funded by the Ministry of Science and Higher Education.

\section{REFERENCES}

Balwierz W (2004) Management strategy in neuroblastoma. Przegl Lek 61 (Suppl 2): 3-8 (in Polish).

Beiske K, Ambros PF, Burchill SA, Cheung IY, Swerts K (2005) Detecting minimal residual disease in neuroblas- 
toma patients - the present state of the art. Cancer Lett 228: 229-240.

Brodeur GM (2003) Neuroblastoma: biological insights into a clinical enigma. Nat Rev Cancer 3: 203-216.

Carubia JM, Yu RK, Macala LJ, Kirkwood JM, Varga JM (1984) Gangliosides of normal and neoplastic human melanocytes. Biochem Biophys Res Commun 120: 500504.

Chang HR, Cordon-Cardo C, Houghton AN, Cheung NK, Brennan MF (1992) Expression of disialogangliosides GD2 and GD3 on human soft tissue sarcomas. Cancer 70: 633-638.

Chen S, Caragine T, Cheung NK, Tomlinson S (2000) Surface antigen expression and complement susceptibility of differentiated neuroblastoma clones. Am J Pathol 156: 1085-1091.

d'Azzo A, Tessitore A, Sano R (2006) Gangliosides as apoptotic signals in ER stress response. Cell Death Differ 13: 404-414.

Evans AE, Baum E, Chard R (1981) Do infants with IVS neuroblastoma need treatment? Arch Dis Child 56: 271274.

Hakansson L, Fredman P, Svennerholm L (1985) Gangliosides in serum immune complexes from tumour-bearing patients. J Biochem 98: 843-849.

Hakomori S (2001) Tumour-associated carbohydrate antigens defining tumour malignancy: basis for development of anti-cancer vaccines. Adv Exp Med Biol 491: 369-402.

He X, Dagan A, Gatt S, Schuchman EH (2005) Simultaneous quantitative analysis of ceramide and sphingosine in mouse blood by naphthalene-2,3-dicarboxyaldehyde derivatization after hydrolysis with ceramidase. Anal Biochem 340: 113-122.

Hettmer S, Malott C, Woods W, Ladisch S, Kaucic K (2003) Biological stratification of human neuroblastoma by complex "B" pathway ganglioside expression. Cancer Res 63: 7270-7276.

Hettmer S, McCarter R, Ladisch S, Kaucic K (2004) Alterations in neuroblastoma ganglioside synthesis by induction of GD1b synthase by retinoic acid. Br J Cancer 91: 389-397.

Hettmer S, Ladisch S, Kaucic K (2005) Low complex ganglioside expression characterizes human neuroblastoma cell lines. Cancer Lett 225: 141-149.

Kong Y, Li R, Ladisch S (1998) Natural forms of shed tumour gangliosides. Biochim Biophys Acta 1394: 43-56.

Ladisch S, Gillard B (1987) Isolation and purification of gangliosides from plasma. Methods Enzymol 138: 300306.

Ladisch S, Wu ZL, Feig S, Ulsh L, Schwartz E, Floutsis G, Wiley F, Lenarsky C, Seeger R (1987) Shedding of GD2 ganglioside by human neuroblastoma. Int J Cancer 39: 73-76.

Ladisch S, Li R, Olson E (1994) Ceramide structure predicts tumour ganglioside immunosuppressive activity. Proc Natl Acad Sci USA 91: 1974-1978.

Li R, Ladisch S (1991) Shedding of human neuroblastoma gangliosides. Biochim Biophys Acta 1083: 57-64.

Liour SS, Kapitonov D, Yu RK (2000) Expression of gangliosides in neuronal development of P19 embryonal carcinoma stem cells. J Neurosci Res 62: 363-373.
Mujoo K, Kipps TJ, Yang HM, Cheresh DA, Wargalla U, Sander DJ, Reisfeld RA (1989) Functional properties and effect on growth suppression of human neuroblastoma tumors by isotype switch variants of monoclonal antiganglioside GD2 antibody 14.18. Cancer Res 49: 2857-2861.

Neville DC, Coquard V, Priestman DA, te Vruchte DJ, Sillence DJ, Dwek RA, Platt FM, Butters TD (2004) Analysis of fluorescently labeled glycosphingolipid-derived oligosaccharides following ceramide glycanase digestion and anthranilic acid labeling. Anal Biochem 331: 275-282.

Perez CA, Ravindranath MH, Soh D, Gonzales A, Ye W, Morton DL (2002) Serum anti-ganglioside IgM antibodies in soft tissue sarcoma: clinical prognostic implications. Cancer J 8: 384-394.

Ravindranath MH, Gonzales A, Soh D, Nishimoto K, Tam WY, Bilchik A, Morton DL, O'Day S (2001) Interleukin2 binds to ganglioside $\mathrm{GD}(1 \mathrm{~b})$. Biochem Biophys Res Commun 283: 369-373.

Riley RD, Heney D, Jones DR, Sutton AJ, Lambert PC, Abrams KR, Young B, Wailoo AJ, Burchill SA (2004) A systematic review of molecular and biological tumour markers in neuroblastoma. Clin Cancer Res 10: 4-12.

Schumacher-Kuckelkorn R, Hero B, Ernestus K, Berthold F (2005) Lacking immunocytological GD2 expression in neuroblastoma: report of 3 cases. Pediatr Blood Cancer 45: 195-201.

Shimada H, Ambros IM, Dehner LP, Hata J, Joshi VV, Roald B, Stram DO, Gerbing RB, Lukens JN, Matthay KK, Castleberry RP (1999) The international neuroblastoma pathology classification (the Shimada system). Cancer 86: 364-372.

Sietsma H, Nijhof W, Dontje B, Vellenga E, Kamps WA, Kok JW (1998) Inhibition of hemopoiesis in vitro by neuroblastoma-derived gangliosides. Cancer Res 58: 4840-4844.

Svennerholm L (1980) Ganglioside designation. Adv Exp Med Biol 125: 11.

Valentino LA, Ladisch S (1992) Localization of shed human tumour gangliosides: association with serum lipoproteins. Cancer Res 52: 810-814.

Valentino L, Moss T, Olson E, Wang HJ, Elashoff R, Ladisch S (1990) Shed tumour gangliosides and progression of human neuroblastoma. Blood 75: 1564-1567.

Varki A (1999) Glycosylation changes in cancer. In Essentials of Glycobiology. Varki A, Cummings R, eds. Cold Spring Harbor Laboratory Press, New York.

Weinstein JL, Katzenstein HM, Cohn SL (2003) Advances in the diagnosis and treatment of neuroblastoma. Oncologist 8: 278-292.

Wing DR, Garner B, Hunnam V, Reinkensmeier G, Andersson U, Harvey DJ, Dwek RA, Platt FM, Butters TD (2001) High-performance liquid chromatography analysis of ganglioside carbohydrates at the picomole level after ceramide glycanase digestion and fluorescent labeling with 2-aminobenzamide. Anal Biochem 298: 207-217.

Wu ZL, Schwartz E, Seeger R, Ladisch S (1986) Expression of GD2 ganglioside by untreated primary human neuroblastomas. Cancer Res 46: 440-443. 